\title{
Adultos maduros e informática: o mouse no caminho
}

\section{Mature adults and computing: the mouse in the way}

\section{Resumo:}

O presente trabalho investiga o desenvolvimento da habilidade do uso do mouse de pessoas com mais de 45 anos durante cursos de introdução no uso do computador. Através da análise de observações realizadas nos momentos de aula verificamos oito tipos de dificuldades encontradas pelos alunos. O cruzamento das observações com dados como idade, profissão, contatos com computador e escolaridade apontam para fatores que podem intervir no processo de aquisição de habilidades na aprendizagem do uso do mouse.

PALAVRAS CHAVES: Educação de adultos. Envelhecimento. Inclusão digital. Dificuldades com o uso do mouse.

\section{Abstract:}

The present study analyses the development of the ability to use the mouse of persons with more than 45 years during computer courses for beginners. Based on observations during classes it was possible to register eight tips of difficulties among the students. The crossing of observations with data such as age, occupation, education and contacts with computer point to factors that may intervene in the process of acquiring skills in learning to use the mouse.

Keywords: Adult education. Aging. Digital inclusion. Difficulties on using the mouse.
HOLLERWEGER, Leonéia; ALMEIDA, Sionara Tamanini de; DOLL, Johannes. Adultos maduros e informática: o mouse no caminho. Informática na Educação: teoria \& prática, Porto Alegre, v. 13, n. 1, p. 167-179, jan./jun. 2010.

\section{Leonéia Hollerweger Sionara Tamanini de Almeida Johannes Doll Universidade Federal do Rio Grande do Sul}

\section{Introdução e contexto da pesquisa}

A informática tem provocado mudanças profundas no meio social com reflexos tanto no campo profissional quanto nas vidas particulares. Porém, não todos os membros das sociedades contemporâneas foram incluídos neste processo. Estudos sobre a exclusão do mundo digital apontam que a participação neste mundo é, além da classe social, principalmente uma questão de geração, onde as pessoas com mais idade ainda pouco participam (DATAFOLHA, 2007; DOLL, 2007). Este fato motivou a organização de um projeto de pesquisa e extensão na UFRGS voltado a oferecer cursos de introdução à informática para pessoas com 45 anos ou mais ${ }^{1}$ e estudar os processos de aprendizagem, bem como o impacto destes cursos na vida profissional

1 De acordo com a Organização Mundial da Saúde, a partir da idade de 45 se iniciam as perdas de algumas capacidades funcionais nas pessoas que podem se refletir em qualquer atividade humana, principalmente no trabalho (IPEA, 2006). 
e privada. Os resultados deste projeto já foram apresentados em congressos e publicações nacionais e internacionais (DOLL, 2002a, DOLL, 2002b, DOLL, 2003, DOLL, 2004, BUAES, 2004, PARENZA; RIBEIRO; SIMIONATO et al., s/d, DOLL; BUAES; RAMOS, 2008). Desta forma, o presente trabalho sobre o uso do mouse se insere em uma produção maior sobre a inclusão digital de pessoas adultas e idosas.

Durante os cursos de introdução ao uso do computador chamou a atenção as dificuldades que uma boa parte dos participantes enfrentou com o mouse e a demora em adquirir a habilidade para utilizá-lo. É possível trabalhar com um computador sem o uso do mouse, mas os sistemas atuais com suas superfícies gráficas tornaram seu uso tão comum que a grande maioria dos usuários não consegue mais nem desligar o computador sem este periférico. Desta forma, dificuldades no uso do mouse podem representar, para um iniciante, uma barreira séria até o ponto de desistir do uso do computador.

Uma revisão bibliográfica demonstrou que estes problemas já foram observados por outros autores, principalmente em relação a pessoas com mais idade, (CHOU; HSIAO, 2007, KACHAR, 2003, SCHWARTZ; FERREIRA; PALAZZO, s/d). Mas os trabalhos encontrados ficaram principalmente na nomeação do problema sem analisar mais a fundo esta questão.

O presente trabalho visa uma aproximação às dificuldades do uso do mouse como uma ferramenta chave para o uso do computador. Como não se dispõe de outros estudos sobre o assunto e pelas especificidades do grupo analisado, isto é, um grupo não representativo com número relativamente pequeno de participantes, o presente estudo possui um caráter exploratório.

\section{Lidar com o mouse: reflexões preliminares}

O periférico conhecido como mouse foi inventado em 1964 por Douglas Engelbart, como XY Position Indicator For A Display System, mas foi somente a partir da década de 80 que o mouse passou a ter maior utilidade nos $\mathrm{PCs}^{2}$. Até então, a maneira de movimentar o cursor era realizada a partir de comandos via teclado. Com o desenvolvimento das superfícies gráficas utilizando ícones, o mouse se tornou uma ferramenta amigável para abrir programas, deslocar o cursor, selecionar trechos de textos ou dados, etc. Paralelamente a isso, o perfil dos usuários do computador começou a mudar e cada vez mais pessoas começaram a utilizar o PC não querendo se preocupar com sequências de comandos a serem decorados. Desta forma, o mouse se tornou um dos periféricos mais importantes e muitas pessoas que utilizam o computador são incapazes de trabalhar sem este recurso ou um parecido como o touchpad ${ }^{3}$.

Enquanto o uso do mouse não parece causar maiores dificuldades entre jovens aprendizes de computação, existem uma série de relatos em estudos sobre a inclusão digital de pessoas adultas maduras e idosas pontuando dificuldades que este grupo apresenta no uso do periférico (CHOU; HSIAO, 2007, KACHAR, 2003, SCHWARTZ; FERREIRA; PALAZZO, s/d). Mas, como já ressaltado, estes estudos não trazem pistas sobre possíveis causas. Por isso, o grupo de pesquisa decidiu realizar um estudo exploratório a respeito das dificuldades do uso do mouse, utilizando diferentes instrumentos de levantamento de dados.

\section{Metodologia}

O estudo utilizou como metodologia e técnica principal de coleta de dados a observação, além do levantamento de dados sóciodemográficos dos participantes. A coleção de dados da observação foi realizada de três formas diferentes. Primeiramente foram feitas observações de cunho descritivo visando registrar, em detalhes, de que forma os participantes lidaram com o mouse. A segunda forma de observação foi através de uma ficha de observação, construída a partir de experiências em cursos anteriores. Esta ficha abrange 10 tópicos e foi elaborada para poder acompa-

\section{Personal Computers.}

3 O touchpad é um periférico utilizado principalmente em computadores portáteis e possui as mesmas funções do mouse, só que o movimento do cursor acontece através do toque em uma superfície sensível. 
nhar o desenvolvimento dos participantes durante o curso. Para este artigo foram utilizados os dados em relação a um dos tópicos que se refere à habilidade de lidar com o mouse. O observador deve classificar o empenho do participante em uma escala de 1 a 5 , sendo os diferentes graus descritos da seguinte forma:

1 - segurança no manejo do mouse, facilidade no posicionamento do cursor, facilidade para selecionar palavras;

2 - executa as tarefas, mas fraciona o movimento ${ }^{4}$;

3 - segura o mouse com a ponta dos dedos ou de maneira insegura; dificuldade no posicionamento do cursor e dificuldade para selecionar palavras;

4 - com muitas dificuldades consegue executar as tarefas;

5 - não consegue utilizar o mouse.

As fichas de observação foram aplicadas três vezes em cada curso, no início, na metade e no final do curso. Nos momentos de observação os mesmos observadores foram utilizados para garantir a fidedignidade da observação.

A terceira forma de observação foi através de fotografias que foram feitas dos alunos na sua interação com o computador e mouse. Uma média de quatro fotos dos alunos foi realizada em cada momento de aula, totalizando 172 fotos. A opção pelas fotos se deu em função de se obter um registro da situação analisada e para evitar distorções no momento da análise. Complementando as categorias de análise por meio linguístico, as imagens foram uma forma de ilustrar as dificuldades dos alunos frente ao uso do mouse (PENN, 2002, THIEL, 1991). Os dados dos registros fotográficos mereceriam uma análise e interpretação específica porém, neste trabalho, foram utilizados somente como apoio aos pesquisadores para analisar as dificuldades.

Os dados foram coletados durante as três edições do Curso de Introdução ao Uso do Computador realizado no ano de 2006.
As aulas aconteceram no laboratório de informática da Faculdade de Educação (LIES/ UFRGS). Cada curso possuiu oito aulas, com carga horária total de vinte horas divididas em dois encontros por semana no turno da noite. O currículo do curso foi constituído de conhecimentos básicos em microinformática tais como: componentes do computador, uso de teclado e mouse, ferramentas de Windows, editor de textos e Internet.

A participação no curso foi aberta à comunidade, sendo divulgado através de um anúncio em um jornal. $\mathrm{O}$ anúncio foi dirigido a pessoas com mais que 45 anos sem conhecimentos prévios do computador. A inscrição foi a partir da ordem de chegada. Participaram nos três cursos um total de 43 pessoas, dentre estes, 13 homens e 30 mulheres. A média de idade dos participantes ficou em 58,4 anos. Do total de alunos, 21 são aposentados e os 22 restantes são trabalhadores de diferentes segmentos econômicos.

Os cursos contaram, além do professor, com tutores que estavam sempre a disposição para ajudar os participantes sem que estes precisassem recorrer ao professor. A organização se mostrou adequada para o público alvo. Estes tutores, alunos da iniciação científica e mestrandos, tinham também a função de observar os alunos, realizar entrevistas e preencher as fichas de observação.

\section{Apresentação dos dados e discussão dos resultados}

\subsection{Observação Geral}

Durante os cursos, professores e tutores observaram a interação dos participantes com o mouse e nas reuniões de pesquisa foram levantadas as dificuldades observadas. Não foram todos os participantes que apresentaram dificuldades, elas variavam entre as pessoas. Mas, de forma geral, foram observadas as dificuldades que constam na Tabela 1. ação. 
TABELA 1 - Dificuldades Encontradas Pelos Alunos no Uso do Mouse

Segurar o mouse com a ponta dos dedos;

Insegurança: poucos e pequenos pontos de contato com o mouse;

Movimento fracionado;

Tensão e excesso de força para clicar no botão do mouse;

Lentidão na execução das tarefas;

Realização de movimentos látero-laterais ao invés de antero-posteriores para usar o mouse;

Dificuldade de utilização do espaço do mousepad, restringindo-se ao lado direito extremo da mesa;

Movimentos de pequena amplitude com o mouse*

* A dificuldade para posicionar o cursor na tela se daria em função dos movimentos de pequena amplitude com o mouse.

As pessoas, de uma forma geral, utilizam o mouse quando acessam as ferramentas virtuais do computador, clicando sem dirigir o olhar a ele, ficando a atenção voltada para a tela do computador. Entretanto, durante os cursos foi verificado que alguns alunos concentravam a atenção no mouse olhando o seu movimento e ao clicar, esqueciam que o comando ocorria na tela do computador. Muitos perguntavam: onde o cursor foi parar? não sabendo onde clicaram, uma vez que sua atenção tinha sido voltada para o mouse e não para a tela.

Aprender a usar o mouse exige alguns esforços, principalmente para aquelas pessoas que não haviam tido contato anterior com o computador. Para os alunos que fracionavam o movimento ficava clara a necessidade de movimentação dos olhos e da cabeça para o uso do mouse, ou seja, o olhar se dirigia para ele, a fim de que o clique no botão esquerdo fosse concluído. Mas isso não foi o suficiente para que a tarefa no computador fosse completada com sucesso.

Existem evidências, segundo Woollacott e Shumway-Cook (2003), de que os movimentos oculares e manuais influenciam um ao outro, tornando os movimentos manuais mais exatos quando associados ao movimento ocular. No entanto, para a tarefa específica do computador essa ação não é eficiente, pois a tarefa estaria sendo exercida na tela do computador e não no mouse.

Essa falta de experiência poderia ser um fator adicional às dificuldades encontradas pelos alunos, pois a sua manipulação seria algo inédito, sendo necessária a aprendizagem do movimento. Essa é uma hipótese a ser considerada, uma vez que mais da metade dos alunos não havia tido contato anterior com a máquina. Além disso, outros elementos podem ser citados como fatores de dificuldade dos alunos do curso de informática: tensão nos dedos, movimentos de pequena amplitude, excesso de força ao clicar, o que faz com que não haja exatidão no posicionamento do cursor na tela.

Para o controle da mão nas tarefas há fatores que contribuem para o processamento sensório-motor. Os fatores são: idade, experiência com a tarefa, a presença ou ausência de patologia, o tipo de tarefa e as limitações específicas do ambiente, considerando-se as propriedades dos objetos (WOOLLACOTT; SHUMWAY-COOK, 2003).

Nas outras dificuldades encontradas no curso como: segurar o mouse com a ponta dos dedos, realização de movimentos láterolaterais com o mouse ao invés de antero-posteriores, dificuldade de utilização do mousepad; assim como nas dificuldades já citadas, a experiência anterior que este aluno possui com a tarefa ${ }^{5}$ do mouse e a especificidade do tipo de tarefa ${ }^{6}$ podem ser outras explicações de tais dificuldades. Associado a isto, se pode entender que a aprendizagem desses adultos maduros e principalmente dos idosos é mediada por declínios físicos e motores que iniciam nesta idade. Estes podem ser fatores de dificuldades na aprendizagem, pois à medida que o tempo passa e as alterações físicas aparecem há uma modificação no comportamento e na interação com o ambiente (BEE, 1997). O grau de sucesso ou fracasso no desempenho de uma tarefa dependerá da exigência específica da mesma, ou seja, se ela exigir que o indivíduo use um sistema fisiológico que esteja em declínio, o desempenho poderá ficar abai-

5 Aqui também é importante destacar que a biografia de trabalho pode justificar a dificuldade/facilidade com o movimento que deve ser realizado com o mouse, ou seja, o aluno pode ter sido um profissional acostumado a trabalhar com objetos pesados (ramo da metalúrgica) e em função disso a sua interação com o mouse é mais dificultada pelo fato do mouse ser um objeto mais delicado.

6 Tarefa que pode ser denominada de complexa, uma vez que exige movimentos da mão fora do campo visual deste aluno, associado a exigência de precisão durante o movimento. 
xo do esperado, pela redução da funcionalidade do sistema (GALLAHUE; OZMUN, 2001).

Relacionando algumas das alterações físicas que as pessoas experimentam durante os anos, tem-se a do sistema sensorial ${ }^{7}$ que, de uma forma geral, apresenta alterações na sua anatomia e fisiologia com o passar dos anos. Algumas dessas alterações podem estar relacionadas com as mudanças na percepção relatadas nos idosos. Mas com os vários sistemas de feedback que o sistema sensorial possui, nem sempre é possível saber como as alterações específicas da percepção estão referidas com tais mudanças. Muito do que se percebe por meio do sistema sensorial de algum modo pode ser controlado pelo contexto no qual os estímulos ocorrem (MARSH, 1999).

Em relação ao trabalho com o computador, destaca-se o sistema visual que possui grande importância na execução das tarefas e seu comprometimento pode ser uma das razões para experimentar dificuldades na aprendizagem do uso do mouse. O declínio deste sistema e a perda da acuidade visual iniciam nos anos intermediários de vida. A capacidade de focalizar com clareza os objetos que estão próximos deteriora-se com rapidez aos 40 e início dos 50 anos $^{8}$ e acontece por alterações no cristalino e na musculatura dos olhos (BEE, 1997). O déficit muscular encontrado também traz uma diminuição na habilidade de acompanhar objetos em movimentos juntamente com a habilidade focalizadora mais fraca (CASE e WATERHOUSE, 1994, GALLAHUE; OZMUN, 2001). Isso nos permite apontar que na relação com o computador esses fatores podem trazer problemas de adaptação do aluno com a máquina e, por conseqüência, na sua aprendizagem.

Outra alteração física que pode contribuir para as dificuldades com o manejo do mouse são as alterações articulares com a conseqüente redução de mobilidade e perda progressiva da flexibilidade de ligamentos e tendões. Elas podem dificultar o movimento da mão que o aluno deve fazer na sua interação com o mouse. As alterações articulares podem ser atribuídas pelas modificações do colágeno e elas-

7 O sistema sensorial como um todo compreende a visão, a audição, o olfato e o tato.

8 Com a falta da capacidade de focalizar os objetos que estão próximos os adultos passam a segurar os objetos cada vez mais distantes, pois somente assim conseguem uma imagem clara (BEE, 1997). tina, elementos que compõem os tecidos e as perdas de flexibilidade ligamentar e tendínea que se atribui à perda de água no tecido conjuntivo (VANDERVOOT, 1998). Durante o curso foi comum falas do tipo: sinto minha mão pesada, é difícil de mover o mouse evidenciando a dificuldade do movimento da mão.

Apesar das alterações físicas que acometem as pessoas a partir dos 40 anos, a questão cognitiva permanece sem profundas modificações (caso o indivíduo não seja acometido por nenhuma doença) e se mantém estável até uma idade madura mais avançada. Elas são geralmente mantidas em bom estado, a não ser por algumas habilidades não exercitadas ou no caso daquelas que requeiram velocidade. A perda da memória é pequena, a produtividade criativa também parece permanecer elevada durante a meia idade, pelo menos nos trabalhos em que os indivíduos sejam desafiados (BEE, 1997).

\subsection{Considerações através da ficha de observação}

A segunda forma de observação foi realizada através de fichas de observação, onde os observadores classificaram o empenho dos participantes entre 1 (muito bom) e 5 (muito ruim) no uso do mouse em três momentos: no início, na metade e no final do curso. Estes dados permitem, por um lado, observar e comparar o empenho dos participantes e, por outro lado, demonstrar o desenvolvimento durante o curso. Também permite uma análise estatística cruzando esta informação com outros dados, o que será feito mais adiante. Importante destacar ainda que, frente ao caráter exploratório da pesquisa e ao número reduzido dos participantes, os resultados precisam ser interpretados com cautela.

O uso do mouse é uma experiência que para muitos passa despercebida, uma vez que aprendido o movimento ele é executado de forma automatizada sem exigir a atenção do usuário experiente. No entanto, para aquelas pessoas que estão se familiarizando com o periférico, essa tarefa não é tão fácil. Os dados da ficha de observação demonstram que aproximadamente a metade dos participantes já teve contato com o computador e já lidava com o mouse de forma competente, enquanto a outra metade demonstrou problemas. No 
final do curso, a grande maioria conseguiu vencer o desafio do mouse, mas continuavam três participantes com dificuldades em utilizar o periférico (Tabela 2).

TABELA 2 - Distribuição dos Participantes Segundo Graus de Competência em Lidar com o Mouse

\begin{tabular}{|l|c|c|}
\hline & $\begin{array}{c}\text { Início do } \\
\text { curso }\end{array}$ & $\begin{array}{c}\text { Final do } \\
\text { curso }\end{array}$ \\
\hline $\begin{array}{l}1 \text { - segurança no } \\
\text { manejo do mouse, }\end{array}$ & 21 & 32 \\
\hline $\begin{array}{l}\text { 2- executa as } \\
\text { tarefas, mas fraciona } \\
\text { o movimento; }\end{array}$ & 7 & 7 \\
\hline $\begin{array}{l}3-\text { uso com certas } \\
\text { dificuldades }\end{array}$ & 10 & 2 \\
\hline $\begin{array}{l}4-\text { com muitas } \\
\text { dificuldades consegue } \\
\text { executar as tarefas; }\end{array}$ & 3 & 1 \\
\hline $\begin{array}{l}5-\text { não consegue } \\
\text { utilizar o mouse }\end{array}$ & 2 & 0 \\
\hline
\end{tabular}

Para analisar mais detalhadamente o desenvolvimento na utilização do mouse em relação a outros dados, os participantes foram agrupados em três grupos:

grupo dos participantes que dominavam desde o início o mouse (índice 1 no início e no final do curso);

grupo dos participantes que no início tiveram dificuldades mas chegaram a utilizar o mouse no final do curso de forma competente (índice 2, 3, 4 ou 5 no início do curso, índice 1 no final do curso);

grupo dos participantes que começaram com muitas dificuldades para executar as tarefas na utilização do mouse e que demonstraram melhoras durante o curso porém, sem chegarem a lidar, de forma tranquila, com este equipamento (índice 2, 3, 4 ou 5 no início e no final do curso).

\subsubsection{Grupo 1 (sem] dificuldades desde o início)}

Uma característica comum a todos os alunos deste grupo é a de que haviam tido algum contato anterior com o computador; seja no trabalho ou em casa, eles utilizavam a máquina, mesmo que com algumas dificuldades. Nossa hipótese é a de que, com as aulas e a ajuda dirigida da professora e das monitoras, esses alunos puderam aperfeiçoar suas habilidades, esclarecendo dúvidas e treinando, permitindo-Ihes o aperfeiçoamento e melhorando ainda mais as suas habilidades. O uso do mouse requer um bom desempenho motor, o que caracteriza uma aprendizagem do movi- mento, a automatização (STERNBERG, 2000), coordenando as questões espaciais, precisão do movimento e ajuste da força para pegar o mouse e para o clique. Como esses alunos de alguma forma já utilizaram o computador anteriormente, provavelmente já tinham aprendido o movimento, caracterizado por uma boa motricidade fina. Esses alunos não fracionavam o movimento, sendo o mesmo mais exato, pois atingiam com maior facilidade o ponto que desejavam na tela. Dessa forma, o movimento para lidar com o mouse já havia sido experienciado por eles antes da entrada no curso, garantindo uma aceleração do processo de automatização. Nos aponta Magill (1989) que a aprendizagem refere-se a uma mudança na capacidade do indivíduo executar uma tarefa. Tal fato surge em função da prática, melhorando o desempenho. Em relação a esse grupo, acreditamos que a experiência do contato anterior com o computador e, consequentemente, da manipulação do mouse, contribuíram para potencializar a aprendizagem destes alunos. Este grupo é formado pelos 21 participantes sem problemas desde o início.

\subsubsection{Grupo 2 (dificuldades no início, domínio} no final)

O perfil desse grupo, no qual pertencem 13 participantes, é heterogêneo, alguns já tiveram contato com o computador, mesmo que pouco, como declararam alguns alunos enquanto outros faziam sua estreia ao lidar com a máquina. Neste grupo, todos foram desenvolvendo e aperfeiçoando as suas habilidades durante o curso, o que é visível pelas diferenças entre os valores dos índices iniciais e finais obtidos ao longo do curso. Todos os alunos conseguiram, através da aula, reduzir seus índices até chegarem a um bom desempenho no uso do mouse.

Os alunos estariam durante as aulas modificando a sua capacidade de execução das tarefas, organizando e repetindo a ação motora, inferindo melhora no desempenho e levando à aprendizagem (PELLEGRINI, 2000). As melhoras apresentadas pelos alunos podem indicar um aperfeiçoamento na seleção de informações e da focalização da atenção, pois no início de cada curso era frequente a ocorrência de movimento fracionado, o que caracterizava uma inabilidade para lidar com diferentes informações: direcionar o mouse, 
adaptar o movimento, encontrar os ícones na tela e prestar atenção na professora. O uso do computador exige do aprendiz certa agilidade e capacidade para selecionar informações, além daquelas que estão constantemente no ambiente, como o barulho do ar condicionado, as conversas paralelas e dos estímulos internos: cansaço, preocupações, entre outros sentimentos. Nesse sentido, nos aponta Ladewig (2000) que

[...] a aprendizagem em geral, e também a motora, requer a seleção de informações que podem estar contidas no meio ambiente e/ou fornecidas pelo professor ou monitoras. Para que esta informação seja retida, para posterior interpretação e possível armazenamento na memória de longa duração, o processo da atenção é fundamental [...] (LADEWIG, 2000, p. 62).

A atenção é fundamental no processo de aprendizagem motora, principalmente no seu início, pois o aluno precisa selecionar informações úteis que o permitem melhorar, uma vez que ele precisa pensar e procurar melhores estratégias para aperfeiçoar o movimento. Ajudálo a coordenar a parte motora à perceptiva traz uma maior precisão, afim de que o ícone ou a palavra possa ser selecionado com êxito.

\subsubsection{Grupo 3 (dificuldades no início sem che-} gar a dominar totalmente o mouse)

Esse grupo, que abrange nove participantes, caracterizou-se por apresentar aqueles alunos com maiores dificuldades para lidar com o mouse. Entre os motivos, poderíamos destacar a inexistência de contato anterior com o computador. Foi observado que as pessoas integrantes deste grupo apresentaram elementos em comum que puderam apontar 0 motivo de um desempenho mais baixo: aqueles que possuíam computador em casa, não o utilizavam. Muitos dos alunos também não tinham computador em casa, logo não exercitavam aquilo que aprendiam em aula.

Apesar dos alunos apresentarem índices diversificados no primeiro momento de observação, a grande maioria desse grupo caracteriza-se por melhorar o seu desempenho ao longo das aulas, apesar de não terem obtido o índice 1 , o que caracteriza uma boa habilidade com o mouse. Podemos pensar o processo de aprendizagem motora dessas pessoas de acordo com os modelos teóricos que se de- finem a partir do grau de automatização que está relacionado à prática. São apresentados os estágios que procuram explicar o processo de aprendizagem.

Inexperiente - nas primeiras tentativas, bus-
ca descobrir qual é a tarefa, o que deve fazer
para realizá-la; Intermediário - a tentativa vai
eliminando os movimentos desnecessários, e
com isso descobre como economizar energia e
tempo; a sequencia de movimentos ganha pro-
gressivamente fluência e harmonia; Avançado
("expert") - o executante tem certeza de como
alcançar a meta da ação, com um mínimo gasto
de energia e/ou tempo. (PELLEGRINI, 2000, p.
30, grifos do autor)

Conforme os estágios, os alunos deste grupo, no início do curso, se encontram na fase inexperiente, uma vez que neste período os movimentos são descoordenados, existindo uma grande variação de movimentos na busca de ajuste do movimento para melhor executar as tarefas. Neste caso como apontam os autores, o iniciante:

[...] não se detém a detalhes da tarefa e tem dificuldade em identificar, nos estímulos internos ou externos, aqueles que são relevantes para a ação; apresenta uma grande quantidade de erros sendo que os acertos muitas vezes são ao acaso, o que leva a incertezas sobre como deve agir. (PELLEGRINI, 2000, p. 30)

Apesar de que, na grande maioria, houve avanços e melhoras no empenho da utilização do mouse, observamos alguns casos onde isso não aconteceu, mantendo o empenho igual durante todo tempo ou até regredir em alguns casos. Parece que o processo de aprendizagem não acontece sempre de forma linear. Neste ponto seria interessante realizar um estudo mais específico para poder diferenciar mais o processo de aprendizagem e possíveis fatores que interfiram neste processo.

\subsection{Relações entre empenho na utilização do mouse e outras características}

A habilidade de lidar com o mouse entre adultos maduros e idosos pode depender de uma série de fatores. Entre os fatores possíveis que poderiam influenciar o empenho no uso do mouse foram escolhidos os seguintes quatro: idade, contatos anteriores, escolaridade e profissão. Trata-se de uma primeira aproximação, 
pois cada uma destas três características pode representar diferentes fatores.

\subsubsection{Idade}

Nos dados recolhidos dos alunos do curso há uma certa correlação entre o desempenho no uso do mouse e a idade no sentido de que os participantes mais jovens tiveram uma maior facilidade de lidar com o mouse. Esta correlação, apesar de fraca, alcança o nível de significância. Durante o curso, esta diferença aumenta, o que significa que a correlação entre idade e desempenho no uso do mouse fica mais significativa (Tabela 3). Estes dados apontam para a possibilidade de que pessoas com mais idade avancem mais devagar no processo de lidar com o mouse.

TABELA 3 - Correlação Entre a Idade dos Participantes e os Desempenhos Durante o Curso

\begin{tabular}{|c|c|c|c|c|}
\hline & & MOUSE1 & MOUSE2 & MOUSE3 \\
\hline & $\begin{array}{c}\text { Correlação } \\
\text { de Pearson }\end{array}$ &, 328 &, 334 &, 401 \\
\hline$\frac{0}{0}$ & Significância &, $032 *$ &, $029 *$ &, $008 * *$ \\
\hline \multirow{0}{0}{} &, 008 &, 00 \\
\hline
\end{tabular}

Mouse 1 - desempenho na utilização do mouse no início do curso

Mouse 2 - desempenho na utilização do mouse no meio do curso

Mouse 3 - desempenho na utilização do mouse no final do curso

Correlação de Pearson - correlação entre idade e desempenho, sendo 1,000 uma correlação direta e linear e 0,000 nenhuma correlação entre os fatores

$* \mathrm{p}<0.05$

$* \mathrm{p}<0.05$
$* * \mathrm{p}<0.01$

Porém, deve-se ter um certo cuidado na interpretação destes dados, pois a característica escolhida - a idade cronológica - pode representar diferentes aspectos. Por um lado pode apontar a processos de perdas com o avanço da idade, seja em nível cognitivo (capacidade de relacionar movimentos da mão com movimentos na tela), seja em nível motor (menor flexibilidade na mão, por exemplo). Mas uma idade mais avançada pode apontar também para outro fator, como o nível de escolaridade, já que o alcance da escolarização, bem como evasão e repetência mudaram muito no Brasil durante o século XX. O fato de que a característica "idade" pode representar diferentes fenômenos, ligado ao número relativamente pequeno dos participantes, sugere certa cautela na interpretação dos dados. Em estudos futuros, este aspecto merece maior atenção.

\subsubsection{Contatos anteriores com computador}

É de se esperar que pessoas que já tiveram, antes do curso, contato com computares demonstrassem um desempenho melhor na utilização do mouse. Mas os dados dos participantes destes cursos não confirmam esta hipótese. Entre as 21 pessoas que tiveram contato anterior com o computador, 12 demonstraram um bom domínio, enquanto 9 tiveram algumas dificuldades no uso. Entre as 22 pessoas que indicaram que não tiveram contato anterior com computador, 9 demonstraram um uso competente com o mouse, enquanto 13 tiveram dificuldades. Surpreende a pequena diferença entre estes dois grupos. A partir dos dados disponíveis, não é possível desenvolver uma resposta clara, mas provavelmente seria necessário analisar mais especificamente que tipo de contato os participantes tiveram com o computador para determinar as razões do desempenho.

\subsubsection{Escolaridade}

A escolaridade dos participantes é bem variada, desde ensino fundamental incompleto até ensino superior completo, mas a grande maioria do grupo tem uma formação escolar bem acima da média da população brasileira. De fato, quase a metade (21 participantes) possui ensino superior completo. Comparando o grupo de pessoas com ensino superior completo com o restante, em relação ao uso do mouse, observa-se que no grupo com a melhor escolaridade existe mais pessoas que lidam de forma competente com o mouse (13), enquanto no outro grupo (22 participantes), somente 8 não demonstraram nenhum problema com o mouse. No entanto, a relação não é tão direta, pois entre as pessoas com escolaridade maior também têm vários que demonstraram problemas sérios com o mouse. Uma das explicações possíveis é que pessoas com melhor escolaridade dispõem geralmente de mais recursos e possuem maior facilidade de adquirir um computador. De fato, somente dois deste grupo não tinham computador em casa, enquanto no outro grupo quase a metade (10 pessoas de 22) não possuíam um computador. Esta diferença estende-se ao trabalho do grupo com ensino superior, 7 (de 21) encontraram um computador no seu trabalho contra somente 2 (de 22) do grupo com 
menor escolarização. De fato, no grupo com maior escolarização, mais que a metade (13) relataram contatos anteriores com computador, enquanto no outro grupo, somente 8 (de 22) tinham tido contato com computador.

\subsubsection{Profissões}

Conforme as teorias sobre aprendizagem de adultos, as experiências anteriores das pessoas representam a base sobre a qual as pessoas procuram resolver novos problemas quando surgem (JARVIS, 2006). Desta forma, as experiências profissionais poderiam exercer certa influência sobre a habilidade de lidar com o mouse. Por um lado, pessoas podem desenvolver, a partir da sua atividade profissional, uma boa motricidade fina com a mão quando necessário no exercício da sua profissão. Estas teriam certamente vantagens em relação a pessoas que não exerceram profissões que exigiam mais habilidades finas com a mão, pois a habilidade não é desenvolvida. Um exemplo são as profissões que exigem muita força. Por outro lado, pessoas podem estar acostumadas a lidar com máquinas que exigem uma interação parecida com a de um computador, por exemplo, máquinas de calcular e, por isso, apresentam menos problemas de lidar com o mouse.

Para verificar esta hipótese, analisamos as profissões das pessoas que lidaram tranquilamente com o mouse. De fato, encontramos profissões como dentista e enfermagem bem como profissões que lidam com equipamentos eletrônicos, tais como contador, contabilista e empresário. No grupo das pessoas com mais problemas encontramos profissões como torneiro mecânico, transporte escolar, cozinheira ou ascensorista. A profissão mais ambígua, neste sentido, é a do professor. Pois encontramos vários professores, tanto no grupo com excelente empenho quanto no grupo com enormes problemas.

\section{Considerações finais}

A informática é um espaço novo por onde a grande maioria dos alunos maiores de 45 anos do curso se aventurou pela primeira vez. Nesta aventura tiveram que enfrentar ferramentas desconhecidas para poderem lidar com o computador, esta máquina que abre novos meios de interação, de tempos e espaços no universo cultural (LÉVY, 1996). Especialmente uma destas ferramentas, o mouse, é um periférico que causa estranhamento, gera incertezas na forma de agir e requer do aluno capacidade para lidar com o novo e para adaptar seus movimentos e sua forma de perceber e agir. Estudos sobre a capacidade intelectual global de Werner Schaie apontam:

esta como um complexo de diferentes habilidades reunidas em quatro grupos de funcionamento: a inteligência cristalizada que compreende o tipo de habilidade adquirida através da educação formal e informal, a flexibilidade cognitiva, que consiste na habilidade de mudar de uma para outra maneira de pensar dentro de um mesmo contexto, a flexibilidade visual motriz e a visualização (SCHAIE apud BERLINCK; BERLINCK, 1998, p.64-65).

De fato, o trabalho com o computador é, para alguém que não está acostumado, uma experiência extremamente complexa, pois uma série de novas habilidades precisa ser coordenada de uma forma pouco costumeira, especialmente para os participantes com mais idade. Enquanto o uso do teclado ainda pode remeter à máquina de escrever, não existe algo paralelo ao uso do mouse. Desta forma, os participantes têm que aprender tanto movimentos novos com a mão quanto habilidades novas, como relacionar um movimento com a mão com um movimento de um sinal (cursor) na tela do computador. Além disso,exige desenvolver uma coordenação motora nova com a mão segurando um objeto (mouse) e fazer um clique com um dedo. Apesar de o mouse ser somente um dos vários desafios na aprendizagem de lidar com o computador, o seu manuseio representa uma tarefa bastante exigente por necessitar de complexa relação entre habilidades motoras e habilidades cognitivas. Assim, pelo fato do mouse ser hoje um periférico quase imprescindível, o seu domínio ou não pode ser o fator decisivo para uma inclusão ou exclusão digital.

Os dados da presente pesquisa descreveram o desafio que o mouse representou para participantes em cursos de computação. No início do curso mais ou menos a metade tiveram dificuldades. Uma comparação entre o empenho inicial e final no curso demonstrou, por um lado, avanços claros de todos os participantes mas, mesmo assim, quase um quarto deles continuou ainda com certas dificuldades. 
Um cruzamento entre desempenho e características dos participantes (idade, profissão, contato anterior e escolaridade) revelou certas pistas que podem apontar para razões das dificuldades. Nesta pesquisa, a idade, a escolaridade e a profissão demonstraram uma certa relação com maior ou menor desempenho, enquanto contatos anteriores pareciam não ter grande influência. Na discussão dos resultados ficou evidente que estes dados precisam de uma análise ainda mais detalhada e diferenciada. Por um lado, cada uma das características pode englobar outras. Assim, idade cronológica poderia estar vinculada a processos de perda pela idade, mas também à mudanças sóciohistóricas como escolarização em diferentes épocas ou inovação tecnológica. Por outro lado, o próprio desempenho na utilização do mouse, registrado através de uma ficha de observação, precisaria de uma maior análise, pois não consegue diferenciar entre problemas motores, problemas cognitivos ou motivacionais.

A contribuição desse estudo de caráter exploratório consistente principalmente em dois pontos. O primeiro se refere a uma meIhor compreensão das dificuldades possíveis no uso do mouse, que podem ser classificados em quatro aspectos principais:

1 Aspectos motores (motricidade fina);

2 Aspectos sensoriais (visão, tato);

3 Aspectos cognitivos (coordenação mão movimento cursor);

4 Aspectos motivacionais (medos e resistências).

Principalmente $o$ aspecto cognitivo merece um estudo mais detalhado e aprofundado, pois além da habilidade de coordenar o movimento da mão com o do cursor estão envolvidos outros elementos, como a questão de lidar com um excesso de novas informações, a capacidade de manter o foco de atenção e a automatização de certos processos, que libera a atenção para outras tarefas. Em relação a estes elementos, pessoas com mais idade podem ter desvantagens, pois as funções executivas, como atenção seletiva e memória de trabalho, sofrem alterações durante 0 processo de envelhecimento. Em atividades do cotidiano, idosos conseguem compensar estas perdas geralmente pela experiência (KRISTENSEN, 2006) mas, quando se trata de uma tarefa totalmente nova, como traba-
Ihar num computador, não existe esta possibilidade de compensar pela experiência o que pode levar a um menor desempenho. Mas, como já apontado, são necessários estudos mais específicos para determinar com maior precisão as causas das dificuldades no uso do mouse.

O segundo resultado deste estudo é de caráter prático chamando atenção para a necessidade de cuidar da forma como as pessoas continuam a lidar com o mouse, especialmente em cursos de iniciantes que apresentam determinadas características como idade avançada, certos perfis profissionais e escolaridade baixa. Nestas situações deve-se reservar tempo suficiente com exercícios específicos para a utilização do mouse, pois a capacidade de utilização do periférico ${ }^{9}$ influencia diretamente 0 avanço da aquisição de conhecimentos em relação ao computador. Para se obter um avanço na utilização do mouse podem ser utilizados programas de desenho como o Paint (Windows), Tux Paint (Linux), ou também programas específicos para o treinamento do mouse ${ }^{10}$ que permitem aos alunos a exploração do movimento e a precisão no manejo do mouse. É importante que os alunos se acostumem ao formato do mouse e especialmente ao uso das funções dos botões. O reconhecimento do espaço do mousepad pode ser utilizado para a movimentação do mouse, de modo que o aluno perceba o espaço ajudando-o a reduzir os movimentos de pequena amplitude. A exploração dos ícones na tela de forma dirigida primeiramente, e depois, como tarefa livre faz com que os alunos interajam e adquiram maior segurança no uso do mouse. Isso também possibilita a identificação dos ícones, sua memorização aumentando a segurança do aluno no acesso de locais da tela de difícil posicionamento do cursor como, por exemplo, o botão fechar, localizado na extremidade direita e ao alto da tela. O treinamento e reconhecimento do mouse ajudam os alunos com maiores dificuldades a perderem o receio e o medo inicial do contato com o periférico.

As dificuldades apresentadas pelos alunos,

90 acesso à tela pode ser efetuado através do teclado, por meio de teclas de atalho. No entanto, para os nossos alunos que estão iniciando, o mouse é o principal meio de acesso aos recursos oferecidos pelos softwares.

10 Disponível em: <http://www.customsolutions.us/ mouse/Click_square_large/csl-8-click-square-large.htm> Acessado em outubro de 2008. 
seus desempenhos e as sugestões apresentadas neste estudo buscam chamar a atenção para alguns detalhes, muitas vezes não percebidos pelos professores e monitores de informática. A aprendizagem do computador volta-se geralmente para o uso de programas, para a maneira correta de salvar arquivos dentre outros conhecimentos ensinados nos cursos de computação. No entanto, os desafios à aprendizagem podem estar concentrados no mouse. Sendo difícil a interação pela dificuldade de manejo do mouse o aluno sente-se intimidado. Logo, observar os alunos na interação com o mouse permite identificar dificuldades. Isso possibilita o trabalho direcionado para as necessidades do aluno adulto e idoso que lida com o computador, principalmente para aqueles que se aventuram pela primeira vez no mundo digital. A desistência por causa de dificuldades com o mouse seria uma pena, pois o computador oferece, especialmente para adultos maduros e idosos, um número grande de vantagens e possibilidades (BANHATO, 2004).

\section{Referências}

BANHATO, Eliane Ferreira Carvalho et al. Inclusão Digital: ferramenta de promoção para envelhecimento cognitivo, social e emocional saudável? [2004?] Disponível em: <http://pepsic.bvs-psi.org.br/pdf/ph/v5n2/ v5n2a02.pdf> Acesso em: 15 abr. 2010.

BEE, Helen. O Ciclo Vital. Porto Alegre: Artmed, 1997.

BERLINCK, Aldete; BERLINCK, José Augusto. Informática e Longevidade Humana: a interligação entre dois novos fatos sociais. São Paulo: Cabral Ed. Universitária, 1998.

BUAES, Caroline Stumpf. Envelhecimento e Educação: em foco a aprendizagem de trabalhadores mais veIhos. Estudos Interdisciplinares Sobre o Envelhecimento, Porto Alegre, v. 6, p. 7-19, 2004,.

CASE, Richard Maynard; WATERHOUSE, James M.. Human Physiology: age, stress and environment. 2. ed. Oxford: Oxford Science Publ., 1994.

CHOU, Jyh-Rong; HSIAO, Shih-Wen. A usability study on human-computer interface for middle-aged learners. Computers in Human Behavior, Amsterdam, v. 23, p. 2040-2063, 2007.

DATAFOLHA. Instituto de Pesquisa. Os Idosos e a Internet. São Paulo, 2007. Disponível em: <http://aprendiz. uol.com.br/downloads/idoso_internet.ppt> Acesso em: 05 abr. 2010.

DOLL, Johannes. The situation of elderly workers in Brazil. Annual Bulletin of the TALIS Network, Saskatoon, Canadá, n. 12, p. 3-13, 2002a.

DOLL, Johannes. Ältere Arbeitnehmer in Brasilien. In: KARL, Fred; ZANK, Susanne (Org.). Zum Profil der Gerontologie. Kassel: Universitätsbibliothek, 2002b. P. 99-105. (Kasseler Gerontologische Schriften, Band 30)

DOLL, Johannes. Computer learning of elderly industry workers in South Brazil. Convergence: Quarterly Journal of the International Council for Adult Education.Toronto, Canadá, v. 36, n. 1, p. 57-65, 2003.

DOLL, Johannes. A Inclusão Digital de Trabalhadores Mais Velhos: quais são os desafios? RENOTE: Revista Novas Tecnologias na Educação, Porto Alegre, v. 2, n. 1, mar. 2004. Disponível em: <http://seer.ufrgs.br/ renote/article/view/13713/8043> Acesso em : 05 abr. 2010.

DOLL, Johannes. Educação, Cultura e Lazer. In: NERI, Anita Liberalesso (Org.). Idosos no Brasil: vivências, desafios e expectativas na terceira idade. São Paulo: Ed. Fundação Persei Abramo, Ed. SESC-/SP, 2007. P. 109-124. 
DOLL, Johannes; BUAES, Caroline Stumpf; RAMOS, A.C. Inclusão Digital de Adultos Maduros e Idosos: desafios para educação na contemporaneidade. In: SEMINÁRIO DE PESQUISA EM EDUCAÇÃO DA REGIÃO SUL. PESQUISA EM EDUCAÇÃO E INSERÇÃO SOCIAL, 7., 2008, Itajaí, SC. Itajaí, SC: ANPED. 2008.

GALLAHUE, David; OZMUN, John C. Compreendendo o Desenvolvimento Motor: bebês, crianças, adolescentes e adultos. São Paulo: Phorte Ed., 2001.

IPEA. Brasil: o estado de uma nação. Brasília, 2006. Disponível em: <http://www.ipea.gov.br> Acesso em: jun. 2007.

JARVIS, Peter. Toward a comprehensive theory of human learning. Trowbridge: Cromwell, 2006.

KACHAR, Vitória. Terceira Idade e Informática: aprender revelando potencialidades. São Paulo: Cortez, 2003.

KRISTENSEN, Christian Haag. Funções Executivas e Envelhecimento. In: PARENTE, Maria Alice de Mattos et al. Cognição e Envelhecimento. Porto Alegre: Artmed, 2006. P. 97-111.

LADEWIG, Iverson. A Importância da Atenção na Aprendizagem de Habilidades Motoras. Revista Paulista de Educação Física, São Paulo, supl. 3, p. 62-71, 2000.

LÉVY, Pierre. O que é o Virtual? São Paulo: Ed. 34, 1996.

MAGILL, Richard. Motor Learning: concepts and Applications. Dubuque: Iowa Ed. 1989.

MARSH, Gail. Alterações da Percepção com o Envelhecimento. In: BUSSE, E.; BLASER, D. Psiquiatria Geriátrica. 2. ed. Porto Alegre: Artmed, 1999. Cap. 3, p. 63-70.

PARENZA, Cidriana; RIBEIRO, Jorge; SIMIONATO, Margareth et al. A Trajetória de Grupos Etários Maduros: implicações escolares e aprendizagem digital. [S.I.: s.n.], [200-?] Texto digitado.

PELLEGRINI, Ana Maria. A Aprendizagem de Habilidades Motoras I: o que muda com a prática? Revista Paulista de Educação Física, São Paulo, supl. 3, p. 29-34, 2000.

PENN, Gemma. Análise Semiótica de Imagens Paradas. In: BAUER, Martins W.; GASKELL, George. Pesquisa Qualitativa com Texto, Imagem e Som: um manual prático. Petrópolis, RJ: Vozes, 2002. P. 319-342.

SCHWARTZ, Losane Hartwig; FERREIRA, Jean Samarone Almeida; PALAZZO, Luiz Antônio Moro. Informática e Terceira Idade: uma nova perspectiva. Disponível em: <www.ufpel.edu.br/cic/2005/arquivos/CH_01031. rtf> Acessado em: 18 abr. 2010.

STERnBerg, Robert J. Psicologia Cognitiva. Porto Alegre: Artmed, 2000.

THIEL, Teresa. Videotechnique and science: methodological considerations. In: LAMB, M.; KELLER, M. (Org.). Infant development: perspectives from German-speaking countries. Hillsdale: Lawrence Erlbaum, 1991. P. 179-195.

VANDERVOORT, Anthony. Alterações Biológicas e Fisiológicas. In: PICKLES, B.; COMPTON, A.; COLT, C..et al. Fisioterapia na Terceira Idade. São Paulo: Santos Livr. Ed., 1998. Cap. 6, p. 67-79.

WOOLLACOTT, Marjorie; SHUMWAY-COOK, Anne. Controle Motor: teoria e aplicações práticas. 2. ed. [S.I.: Manole, 2003. 
Recebido em agosto de 2008.

Aprovado para publicação em setembro de 2009.

\section{Leonéia Hollerweger}

Graduanda em Pedagogia pela Universidade Federal do Rio Grande do Sul (UFRGS) - Porto Alegre-RS/Brasil. Bolsista PIBIC. Email: leoneiah@yahoo.com.br

\section{Sionara Tamanini de Almeida}

Fisioterapeuta pelo IPA. Licenciatura Plena em Educação Física Universidade Federal do Rio Grande do Sul (UFRGS. Mestranda em Educação pela Universidade Federal do Rio Grande do Sul - Porto Alegre-RS/Brasil. Bolsista Capes.

Email: sionara@cpovo.net

\section{Johannes Doll}

Pedagogo, Especialista em Gerontologia pela Universidade de Heidelberg, Alemanha. Mestre em Educação pela Universidade Federal do Rio Grande do Sul (UFRGS). Doutor em Filosofia pela Universidade de Koblenz, Landau, Alemanha. Professor de graduação e pós-graduação da UFRGS) - Porto Alegre-RS/Brasil.

Email: johannes.doll@ufrgs.br 